\title{
CONSTRUCTING A NOVEL PLASMID TO INCREASE PURITY EFFECTIVENESS FOR RECOMBINANT PROTEINS EXPRESSED IN ESCHERICHIA COLI CELLS
}

\author{
THI-HUYEN TRAN ${ }^{1}$, HOANG-ANH PHAN THI ${ }^{1}$, MINH-NAM NGUYEN $^{2}$, \\ DINH-TRUONG NGUYEN ${ }^{3}$, LIN-WOO KANG ${ }^{3}$ \\ ${ }^{I}$ Industrial University of Ho Chi Minh city, Vietnam, \\ ${ }^{2}$ School of biotechnology, Tan Tao university, Long An, Vietnam, \\ ${ }^{3}$ Konkuk University, Hwayang-dong, Gwangjin-gu, Seoul 143-701, Republic of Korea, \\ tranthihuyen@iuh.edu.vn
}

\begin{abstract}
Nowadays, requirement of supply for recombinant proteins has increased in several fields such as food technology, medical pharmacy, clinical diagnose or environment treatment. The recombinant proteins have become the commercialized products and of that yielded with increasing in a large number per year. Besides, supposing that on extending of the his-tag of the pET111a plasmid may be facilitate for removing his-tag and more effective in protein purification. In this study, nine nucleotides (GCGGCGGCG) coding three alanine residues were added to positions followed hexa-histidine tag (his-tag) on a pET11a plasmid construction. The SDS-PAGE result of each recombinant protein contained the long-modified tag after purification process almost only exhibited single band on gel. Based on alike observed consequences for three recombinant proteins already refined the purity effectiveness reach to upper $98 \%$ in the total of existing proteins inside the solution. Hence, the novel pET11a plasmid construction could become an effective plasmid for the aim of harvesting high-purified recombinant proteins.
\end{abstract}

Keywords. Escherichia coli (E. coli), histidine-tag, pET11a plasmid, purity effectiveness

\section{INTRODUCTION}

Production of soluble recombinant proteins are an important class not only for structure - function analysis, but also applied for therapeutic applications. As pharmaceutical protein development requires having desired pharmacokinetics and physicochemical properties. Thus, an expression system that includes bacterial strains and vectors used to modify protein solubility and stability is really essential for protein development relating to biomaterial matrices, nanoparticles, and vaccines [2-4]. In which, bacterial systems remain most attractive due to low cost, high productivity, and rapid use [5], and Escherichia coli strains are widely used hosts for the production of heterologous proteins for structural and functional studies due to its ability to grow rapidly at high density and in inexpensive substrates [6]. Among of these strains, the $E$. coli strain BL21 (DE3) version carries a chromosomal copy of the gene for bacteriophage T7 RNA polymerase (T7 gene 1) acts under master of the lacUV5 promoter, suitable for protein production from target genes cloned into any $\mathrm{T} 7$ vectors by induction with isopropyl- $\beta$-D-thiogalactopyranosid $[7,8]$. However, the use of bacteria as factories for recombinant expression is limited by their intrinsic tendency to accumulate the target protein into inactive insoluble aggregates, called inclusion bodies [9].

Plasmid is genetic element play a role in providing new genes that promote adaptation to diverse conditions. Plasmid also was known to reduce bacterial competitiveness in the absence of selection for plasmidencoded traits. It is easier to understand plasmid persistence when considering the evidence that plasmid maintenance can improve during co-evolution with the bacterial host, i.e. the chromosome [10]. One of the used expression vector in protein production, pET11a plasmid has characteristic giving satisfaction with the E. coli strains [11]. The plasmid designed to activating through controlled mechanisms of operon lac and expression system of $\mathrm{T} 7$ promoter. 


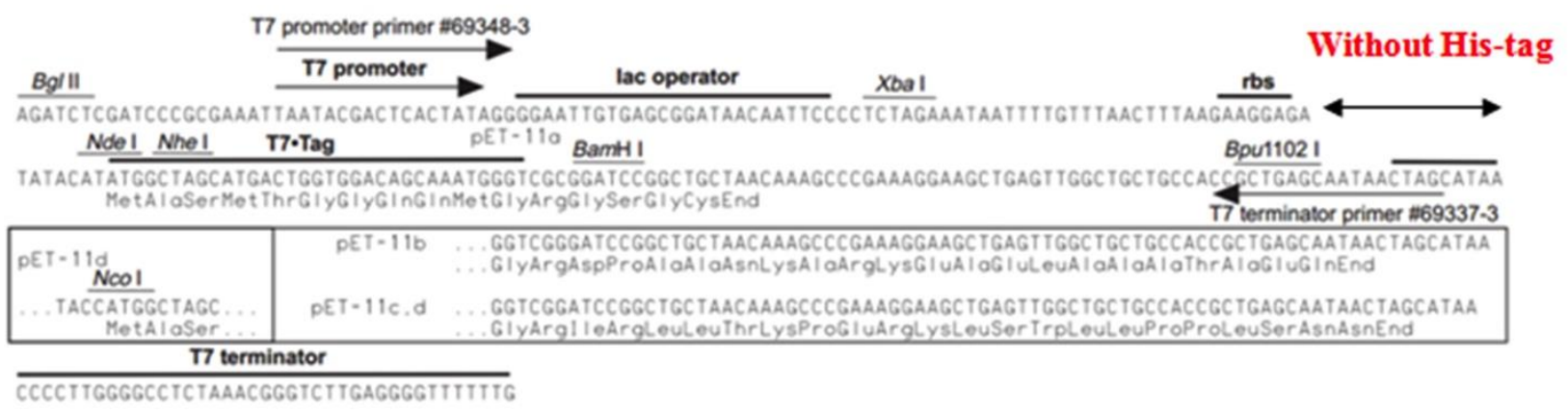

Figure 1.1: Schematic representation of pET-11a cloning/expression region [11]. The original pET11a plasmid only carries an N-terminal T7-tag sequence and BamH1 cloning site and without his-tag or recognize sequence of TEV protease involved in this plasmid. The cloning or expression region of the coding strand transcribed by T7 RNA polymerase.

Recently, the properties, structures, and functions of recombinant proteins are very important considerations for the expression of proteins in vitro. Hence, although many recombinant proteins can be expressed in vitro using various expression systems, but together of the formation of inclusion body, toxicity of exogenous proteins, modification of side-chain, and so forth all influence protein expression that can complicate more to the process of protein purification and then interfere with the biology activity of expressed proteins [12]. Some fusion expression systems (e.g., GST and His-tag) reported that could facilitate protein expression and simplify for protein purification [13]. These purification tags that genetically were fused to the gene of interest are commonly used. The most widely used affinity handle is the hexa-histidine tag (his-tag), which is suitable for purification under both native and denaturing conditions [14].

In practice, affinity tags have become indispensable tools for protein expression and purification. However, all tags, whether large or small, have the potential to interfere with the biological activity of a protein and may impede its crystallization. For this reason, it is usually desirable to remove them from the target protein. Although both chemical and enzymatic reagents have been used to remove tags from recombinant proteins only specific proteases of the tobacco etch virus (TEV) exhibited enough specificity to be generally useful for this purpose $[12,15]$. It should be noted, however, particularly activity of TEV protease can only recognizes the amino acid sequence ENLYFQ/G with high efficiency and cleaves between $Q$ and $G$ [12]. Moreover, a potential limitation of TEV protease is that it is believed to require a Gly or Ser residue in the P1' position (called $\mathrm{X}$ amino acid) of its substrates to process them with reasonable efficiency [16]. Furthermore, as this position of $\mathrm{X}$ amino acid in the recognition site of the TEV protease was substituted by many different residues and then revealed the different kinetic values of Michealis constant $\left(K_{M}\right)$ and turnover number (Kcat) were also determined for a representative set of peptide substrates with amino acid substitutions in the P1' position[16]. Besides, some of the purified proteins were treated with 3C protease (the protease contains recognition sequence is Leu-Glu-Ala-Gln-Thr-Gln*Gly), to cleave non-native sixhistidine tags. But the cleavage was successful in $94 \%$ of 214 attempts response to only cleaved proteins yielded $2.9 \%$, of that much more uncleaved six-histidine-tagged proteins [17].

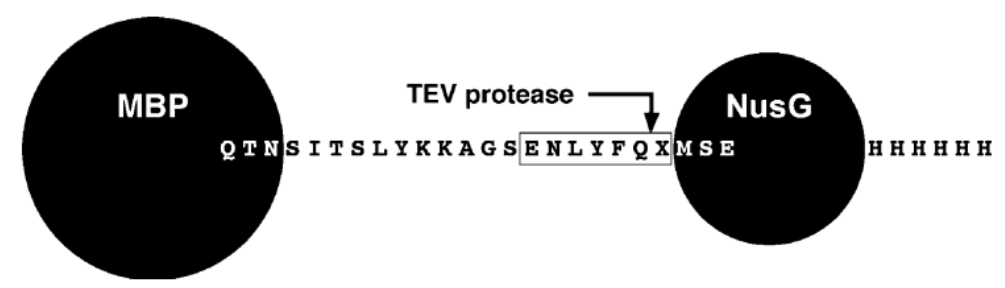

Figure 1.2. Schematic representation of MBP-NusG fusion protein substrates with recognize sequence for TEV protease. The P1' mutated residue in the TEV protease cleavage site is designated " $\mathrm{X}$." [18] 
Kinetic parameters for oligopeptide substrates ${ }^{\mathrm{a}}$ with amino acid substitutions in the $\mathrm{P}^{\prime}$ position

\begin{tabular}{lllc}
\hline P1' residue & $K_{\mathrm{M}}(\mathrm{mM})$ & $k_{\text {cat }}\left(\mathrm{s}^{-1}\right)$ & $k_{\text {cat }} / K_{\mathrm{M}}\left(\mathrm{mM}^{-1} \mathrm{~s}^{-1}\right)$ \\
\hline Ser & $0.043 \pm 0.006$ & $0.194 \pm 0.007$ & $4.51 \pm 0.65$ \\
Gly & $0.087 \pm 0.017$ & $0.268 \pm 0.025$ & $3.08 \pm 0.67$ \\
Ala & $0.090 \pm 0.015$ & $0.271 \pm 0.019$ & $3.01 \pm 0.54$ \\
Met & $0.076 \pm 0.007$ & $0.180 \pm 0.005$ & $2.37 \pm 0.23$ \\
Tyr & $0.050 \pm 0.010$ & $0.031 \pm 0.001$ & $0.62 \pm 0.13$ \\
Asp & $0.057 \pm 0.004$ & $0.021 \pm 0.001$ & $0.37 \pm 0.03$ \\
Gln & $0.321 \pm 0.025$ & $0.073 \pm 0.001$ & $0.23 \pm 0.02$ \\
Glu & $0.094 \pm 0.022$ & $0.014 \pm 0.001$ & $0.15 \pm 0.04$ \\
Lys & $0.224 \pm 0.046$ & $0.027 \pm 0.002$ & $0.12 \pm 0.03$ \\
Leu & $0.240 \pm 0.047$ & $0.014 \pm 0.001$ & $0.06 \pm 0.01$ \\
Val & N.D. & N.D. & $0.010 \pm 0.001$ \\
\hline
\end{tabular}

Table 1.1. Kinetic parameters for oligopeptide substrates with amino acid substitutions in the P1' position [18]

Furthermore, the use of his-tag fusion proteins remain controversial[19]. Here, in this study, we describe a incorporate tool of using hexahistidine-tag (his-tag) and three alanine amino acids on expression vector such as pET11a-his-tag plasmid for the isolation of highly purified his-tagged target proteins using immobilized metal affinity chromatography (IMAC) method. Combining of the analysis of the optimal conditions for the expression and purification of these proteins helped us to design a simple and efficient plasmid for producing and harvesting much more high pure proteins. These results has since been used many of proteins and is illustrated is favorable in large-scale production of recombinant proteins. This approach proves to be low-cost and accessible because it does not require the use of expensive robotic platforms. From the transformation of recombinants into host expression strains to the visualization of expression results on protein gels, to be completed in a week, providing reliable predictions of proteinexpression and IMAC-recoverability levels for large-scale applications within a reasonable timeframe [20, 21].

\section{MATERIALS AND METHODS}

\subsection{Construction of pET11a-His-tag-AAA plasmid}

Based on the success modification of interstation hexa-histidine tag into a purchased original pET11a (pET system vector) performed in our lab. In order to accommodation for purifying target protein, we designed a novel construction from the modified pET11a-his-tag plasmid by addition of nine nucleotides (GCC GCC GCC) coding three alanine residues followed recognition sequence of TEV protease in the plasmid and before recognition site NdeI restriction enzyme. In this study used two primer pairs (the forward primer 5' GGG GGG TCT AGA AAT AAT TTT GTT TAA CTT 3' and the reverse primer 5' GGG GGG CAT ATG GGC GGC GGC TCC CTG AAA ATA CAG 3'), which designed based on an sequence at their 5' ends in the plasmid to making new fragments of $110 \mathrm{bp}$ by PCR methods. Then PCR products were purification by extraction gel kit, and then ligation into the pET11-his-tag expression vector. Finally, the recombinant plasmids were transformed into Escherichia coli (NEB) cell for cloning and expression.

\subsection{Target genes (XoGroEL gene (XOO_4288); Y. pestis ddl gene; C. jejuni pdf gene), bacterial strains and growth media}

Target genes are important genes came from pathogen caused plant and human. Firstly, Y. pestis ddl gene sequences from Yersinia pestis bacteria were optimized for expression in Escherichia coli (BL21-DE3) prior to synthesis and were cloned into the IDT vector (Integrated DNA Technologies, USA), which was then used as a template for amplification of the Y. pestis $d d l$ gene, yielding a $924 \mathrm{bp}$ DNA fragment, using the primers 5'-CCC CCC CAT ATG GCA GAA AAA GTG GCC GTG TTG-3' and 5'-CCC CCC GGA TCC TTA ATA CGC CAG CAT CAG AAT GCG-3'. The bases in bold denote the NdeI and BamHI restriction sites [22]. Seconds, the DNA sequence coding XoGroEL gene (XOO_4288) was amplified using the genomic DNA of X. oryzae pv. oryzae (Xoo; ATCC 10331) as a template and the primers 5'-CCC CCA TAT GGC TGC TAA AGA CAT TCG TTT CGG-3' and 5'-CCC CGG ATC CTC AGA AAT CCA TGC CGC CCA T-3'. The bases in bold indicate NdeI and BamHI restriction sites, respectively) [23]. Finally, the $C$. jejuni pdf gene of Campylobacter jejuni bacteria, encodes a total of 175 amino-acid residues, was 
synthesized (Macrogen, Korea) and used as a template for PCR to amplify the gene, yielding a 549 bp DNA fragment by using the primers 5'-CCC CCC CAT ATG GTG CGC AAA ATT ATT ACC TA-3' and 5'CCC CCC GGA TCC TTA TTT TTC TTT TTT GTG GTT C-3'. The bases in bold designate the NdeI and BamHI digestion sites [24]. All three fragments were double digested with NdeI and BamHI, and subsequently ligated into a pET11a-TEV-AAA expression vector, which was modified to contain an Nterminal 6 His tag followed by a Tobacco etch virus (TEV) protease cleavage site and three alanine residues before the NdeI site to facilitate purification of the expressed protein.

Bacteria strains in this study are Escherichia coli chemically competent strains of NEB and BL21 (DE3) (Novagen), which were used for cloning and gene expression, respectively. The PCR-amplified target gene was cloned first into the pET11a-histag-AAA plasmid and sequenced to exclude amplification errors. For expression and purification, the Escherichia coli BL21 (DE3) strain was transformed with these modified pET11 expression plasmid inserted target genes (Novagen). Bacterial cultures were grown at $37^{\circ} \mathrm{C}$ in LuriaBertani (LB) broth in a shaking incubator or on LB agar plates supplemented with ampicillin $\left(100 \mu \mathrm{g} \mathrm{ml}^{-1}\right)$ as appropriate.

\subsection{Expression and purification of His-AAA-tagged proteins [22, 23, 25]}

Standard cloning procedure of this pET11a-His-tag-AAA plasmid were followed for the generation of all expressed protein constructs. All constructs were verified by DNA sequencing. For each of three target genes such as $Y$. pestis $d d l$ gene, XoGroEL gene, $C$. jejuni $p d f$ gene also used into each His-AAA-tagged plasmid were transformed into Escherichia coli strains BL21 (DE3). Then these proteins named as YpDDL, XoGroEL, CjPDF, and then were expressed in Luria-Bertani media containing $50 \mathrm{mg} \mathrm{ml}^{-1}$ ampicillin. Overexpression of three proteins was induced by adding $0.5 \mathrm{mM}$ isopropyl -d-1-thiogalactopyranoside (IPTG) to the culture at $37^{\circ} \mathrm{C}$ until an $\mathrm{OD}_{600}$ of 0.6 was observed. After induction, the cells were cultured at $25^{\circ} \mathrm{C}$ for an additional $16 \mathrm{~h}$. The cultured cells were harvested by centrifugation for $30 \mathrm{~min}$ at $3000 \mathrm{~g}$ (Supra $30 \mathrm{~K}$ A1000S-4 rotors, Hanil, Seoul, Republic of Korea) at $4^{\circ} \mathrm{C}$ The cell pellets were then resuspended in icecold lysis buffer (25 mM Tris- $\mathrm{HCl} \mathrm{pH} \mathrm{7.5,} 300 \mathrm{mM} \mathrm{NaCl}, 15 \mathrm{mM}$ imidazole, $3 \mathrm{mM}$-mercaptoethanol) and homogenized by ultrasonication (20kHz and $30 \mathrm{~s})$ on ice (Sonomasher, S \& T Science, Republic of Korea). The lysate was then centrifuged for $40 \mathrm{~min}$ at 19960g (Vision VS24-SMTi V508A rotor) at 277 0K to remove the cell debris. The supernatant containing soluble His-AAA-tagged proteins was loaded onto a $\mathrm{Ni}^{2+}$ charged resin (Ni-NTA HisBind Resin, Bio-Rad) to isolate the His-AAA-tagged proteins. The elution fractions of these proteins were then dialyzed in $2 \mathrm{~L}$ digestion buffer $(20 \mathrm{mM}$ Tris- $\mathrm{HCl} \mathrm{pH} \mathrm{8.0,150} \mathrm{mM}$ $\mathrm{NaCl}, 3 \mathrm{mM}$-mercaptoethanol) before removal of the His-tag by His-tagged TEV protease by weight in an overnight reaction. The mixture of reaction was applied onto the $\mathrm{Ni}^{2+}$ charged resin again in order to discard uncleaved the His-tagged proteins and the His-tagged TEV protease. After that, purified fraction ran on SDS-PAGE to detect the ability of TEV protease and analyze purity effectiveness of target proteins by excised bands on SDS-PAGE gel.

Table 2.1. Schematic representation of the target protein fused to pET 11a-His-tag-Tev-AAA plasmid in this study

\begin{tabular}{|c|c|c|c|c|c|c|}
\hline XbaI (RE site) & RBS & His-tag & Tev site & AAA & NdeI (RE site) & Target Protein \\
\hline
\end{tabular}

\section{RESULTS}

\subsection{Analysis pET11a-histag-AAA plasmid construction}

Alanine is a simple amino acid and does not affect the structure of the target gene, in this study, in order to improve the cutting efficiency of TEV protease; we inserted nine nucleotides (GCC GCC GCC) coded three alanine residues into pET11a-His-tag plasmid. By screening annealing temperatures, we found an appropriate PCR protocol for making new 100bp length-fragment involved the above nine nucleotides, specific PCR products showed in Fig. 3.1. Moreover, if having addition of nucleotides coding for both histag and recognition site of TEV protease that known like vital roles in the process of recombinant proteins 
purification[17] Hence, the reliability of exact modifications in our pET11 construction clarified with high affirmation peaks appeared in sequencing result. All sequences of this construction revealed detail in Fig 3.2, in which added nucleotides appeared in their exact positions. More particularly, a glycine residue substituted for serine residues found within the P1' position of TEV protease in our construction and it comprise HSSENYFQ/G residues. It is really valid fundamental midpoint to enhancing remove of his-tag and effective purification of target proteins.

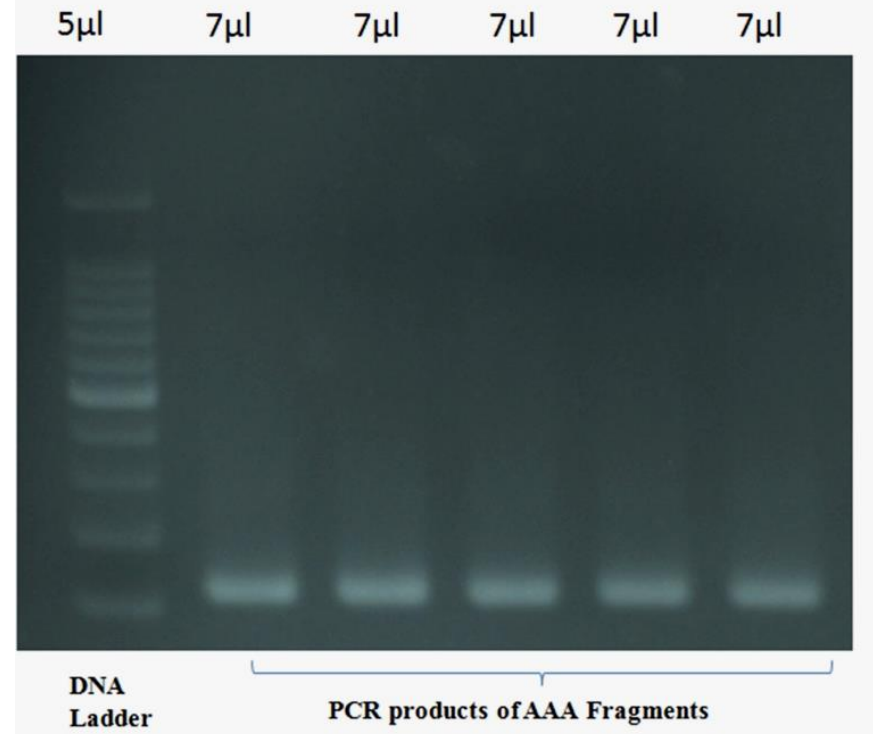

A

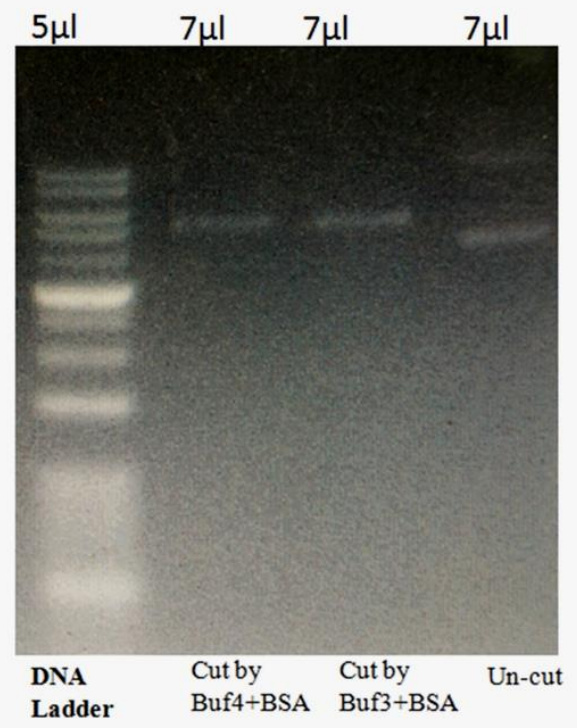

B

Figure 3.1 PCR products and the checked pET11a-histag-construction. A: PCR products of amplifying new fragment contained three codon pair of GCC codding for 3 alanine amino acids. Line 1 (DNA ladder), Line 2-6: PCR products of new fragments (110bp). B: The results of checking digestion of pET11a- His-tag plasmid. Line 1 (DNA ladder); Line 2 (Plasmid cut by 2RE within Buffer 4 plus BSA); Line 3 (Plasmid cut by 2RE within Buffer 3 plus BSA); Line 4 (uncut plasmid)
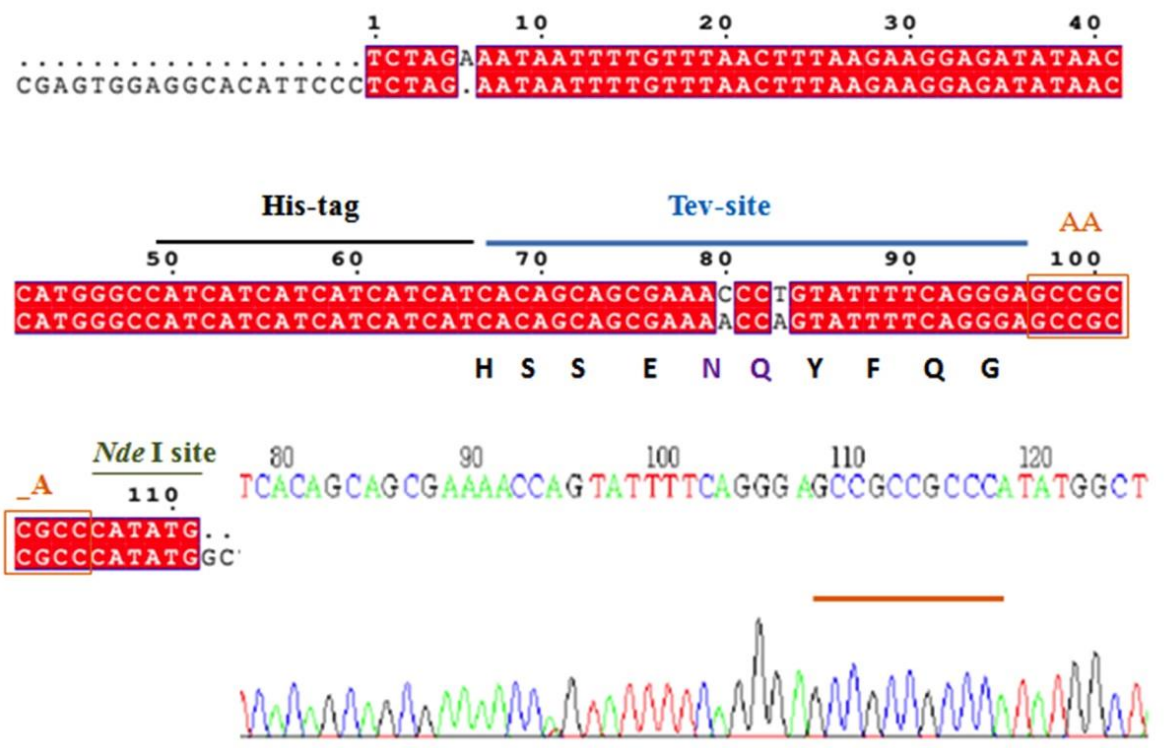

Figure 3.2 Sequencing results of the pET11a-histag-AAA plasmid construction. This construction involved accurate sequences of nucleotide coding for a His-tag (black) next to recognition site of TEV protease (blue) and then three alanine amino acids (orange). And peaks under orange line showed clearly presence of GCC bases coding for three alanine residues. 


\subsection{Sequencing three genes inserted into pET11a-histag-AAA plasmid}

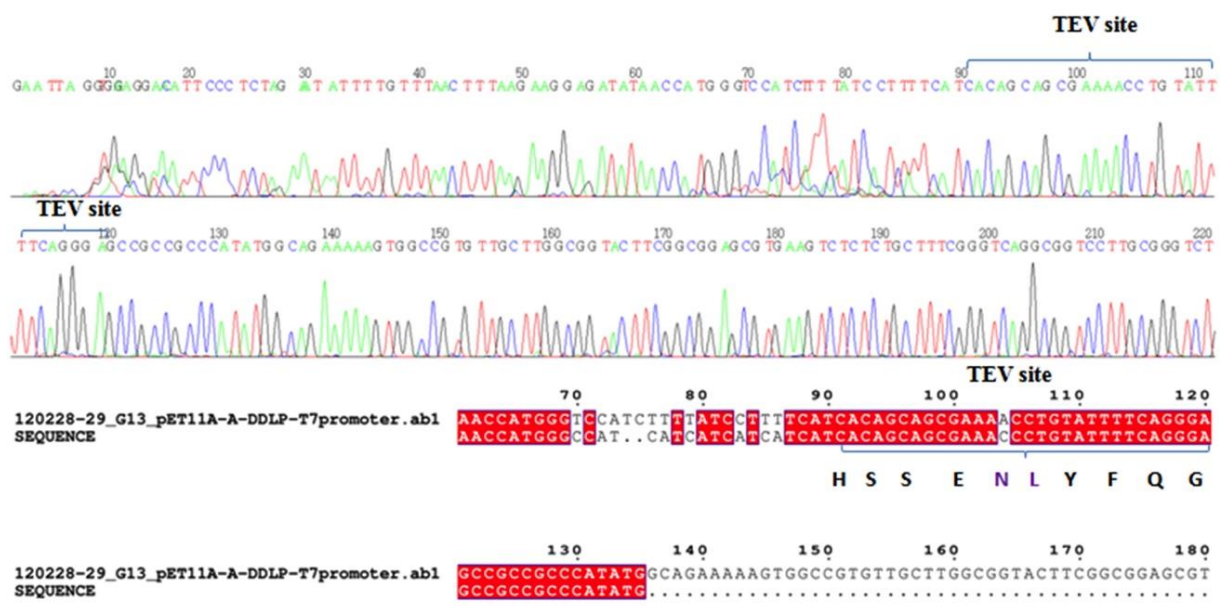

A

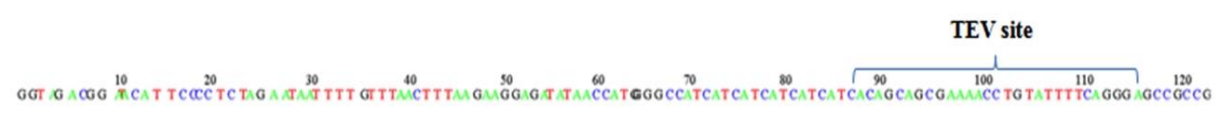

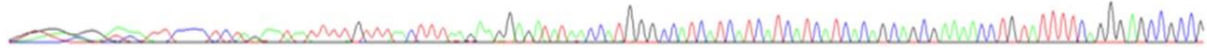

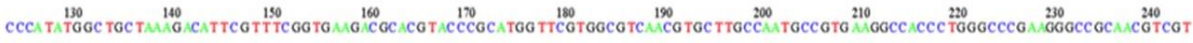

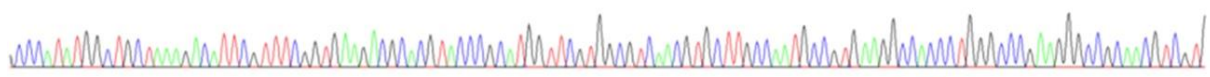

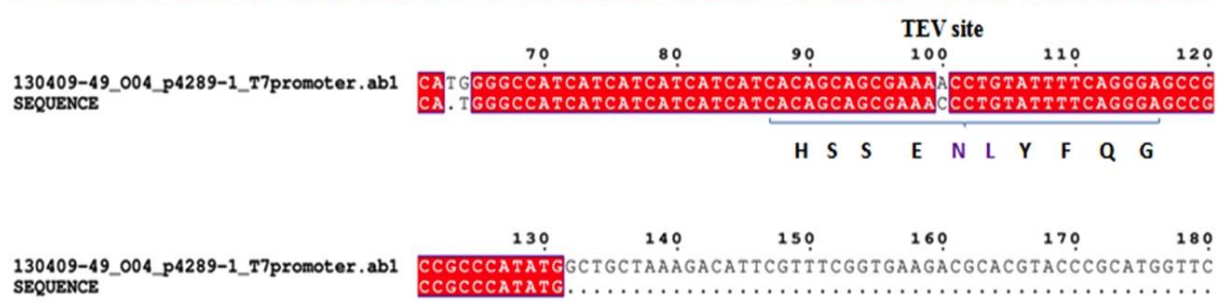
B TEV site
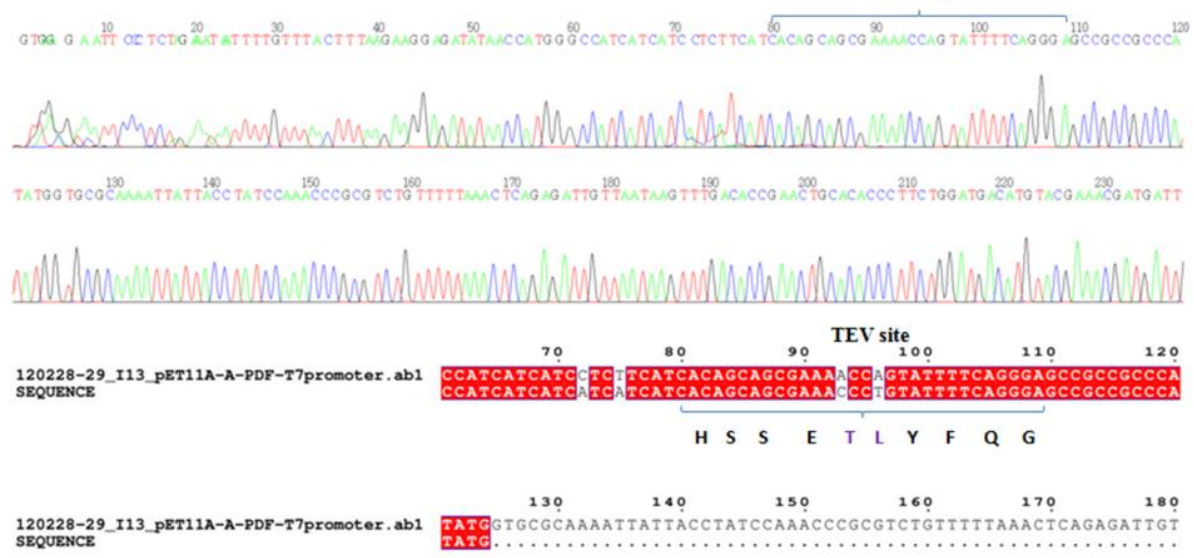

C

Figure 3.3 Analysis sequencing three genes (A: Y. pestis ddl; B: XoGroEL; C: C.jejuni pdf) inserted into pET11ahistag-AAA plasmid. The results of sequencing and sequence alignment of three Fig A, Fig B and Fig C also revealed three target genes exactly ligated into the novel pET11a-his-tag construction, that already carried both TEV recognizing sequence (TLYFQG) and nine nucleotides coding for three alanine residues inside. 
After pET11a-histag-AAA plasmid was formed, we proceeded to attach the target genes to the plasmid to demonstrate the purification effect. In this study, we analyzed three target genes transformed in this modified plasmid ( $Y$. peptis $d d l ;$ XoGroEL and $C$. jejuni pdf genes). A yielded clear and accurate sequence of each target gene showed that we successfully attached the target genes to the plasmid. These plasmids also contained recognize sites of TEV protease and inserted nine nucleotides before start codons of target genes

\subsection{Analysis the results of purified protein by TEV protease}

We continue to purify the protein of the target gene and the results are shown in Figure 3.4. Through extrude his-tag by TEV protease and followed each stages of purification, bands incubated with TEV protease in all three proteins in Fig 3.4 (A, B, C) also grew down as comparing to band without TEV protease. More especially after concentrating processes revealed the final bands are clearly displayed, no strange bands appear, which proves that TEV protease is digested well and high protein purification efficiency. This can be assumed that the his-tag involved in purified recombinant proteins could remove effectively by increasing adhesion and binding ability of TEV protease with three proteins. Placement of the $3 \mathrm{~A}$ site followed the 6-His tag and the protease site allows the use of subtractive IMAC methods during protein purification to further purify the recombinant protein and remove the cleaved tag. This modified plasmid contains the ampR gene which confers resistance to ampicillin for the selection of recombinant constructs during the cloning and expression stages. The purifying efficiency of three proteins are more clearly summarized through Table 3.1, the purity of all three target genes is higher than $95 \%$.
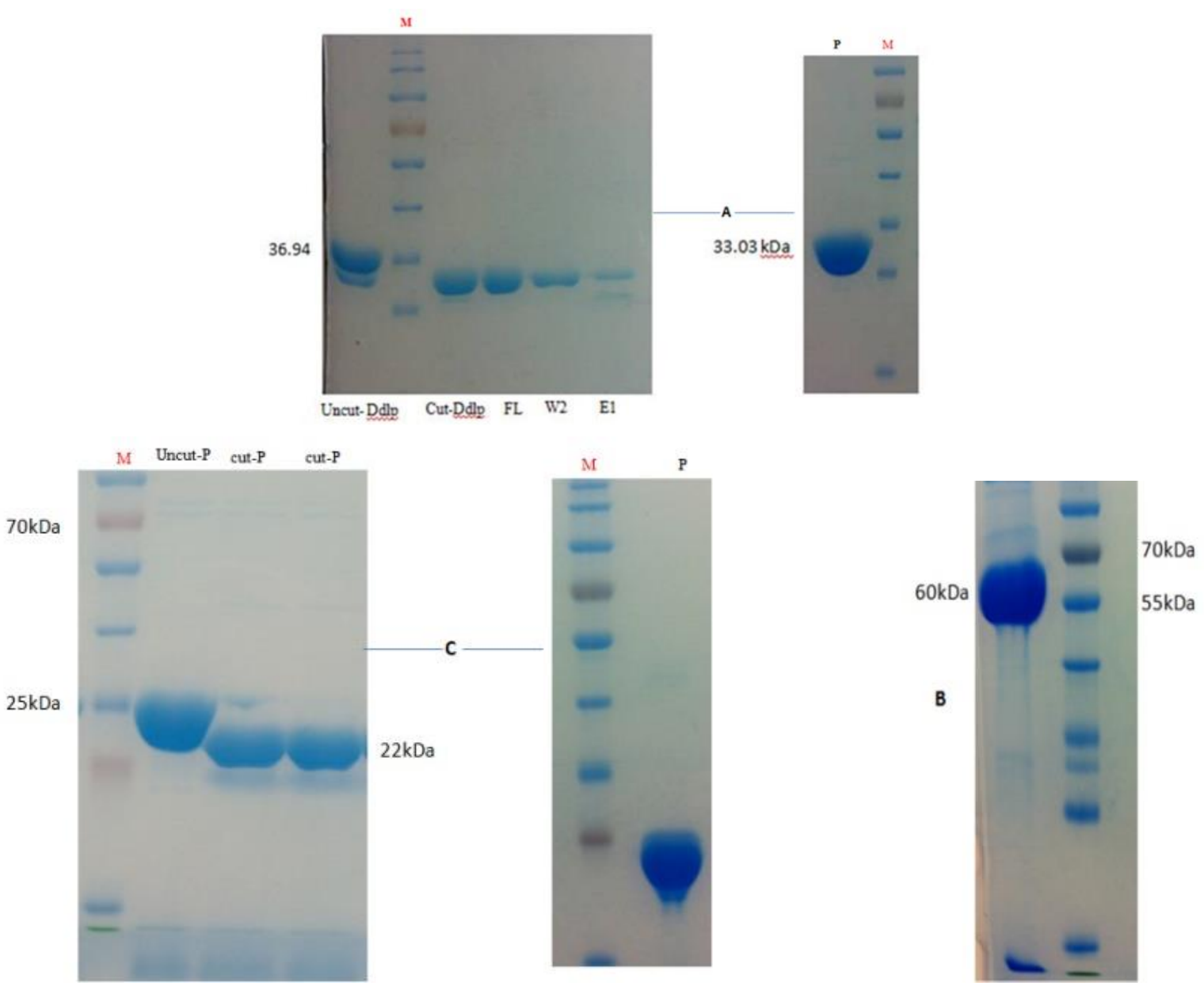

Figure 3.4 The His-tag digesting and purity effectiveness results of three proteins (A: YpDDL; B: XoGroEL; C: $\mathrm{CjPDF}$ ). All bands of three proteins treated TEV protease also grew down on electrophoresis gel (SDS-PAGE) as 
comparing to band without TEV protease in Fig 3.4 (A, B, C), and the high purity of each protein refined in the next image in each Figure A, B and C

Table 3.1. The purifying efficiency of three proteins (YpDDL; XoGroEL; CjPDF) after digesting His-tag by TEV protease.

\begin{tabular}{l|llll}
\hline & Proteins & YpDDL & XoGroEL & CjPDF \\
\cline { 2 - 5 } Efficiency $(\%)$ & His-tag digestion & 98 & 95 & 97 \\
& Purity & 99 & 95 & 99 \\
\hline
\end{tabular}

\section{DISCUSSION}

In addition to the His-tag, the glutathione S-transferase (GST) is also used in purification of proteins, the GST folds rapidly into a stable and highly soluble protein upon translation, inclusion of the GST tag often promotes greater expression and solubility of recombinant proteins than expression without the tag [26]. However, since glutathione affinity chromatography depends on the proper three-dimensional fold of GST, insoluble fusion proteins must be refolded and buffer exchanged before purification; some insoluble proteins may not refold correctly or into a soluble form. Besides, the GST tag is that the large $26 \mathrm{kDa}$ size of the tag and its dimerization in solution may affect the properties of the fusion protein [27, 28]. Both GSTtag and his-tag are equally effective, but His tag has lower molecular weight, does not affect the structure of the protein, providing good cutting efficiency and easy purification of protein[20, 28]. Moreover, his-tag fusion proteins can easily be purified by Ni-NTA affinity resin, yielding 400-700-fold enrichment and gives over $80 \%$ purity on chromatographic step [29].

One advantage of attaching his-tag in producing target recombinant proteins is to enhance protein expression, improving greater stability and solubility of the recombinant protein. However, these targets could be affected the protein structure as the his-tag does not remove out. In a previous study, glycine was attached to the end of the recognize sequence of TEV protease resulted completed cleavage of the fusion tag. It explained that because of the disorder of the six amino acids allow for protease reach to the cleavage site. Therefore, we used three alanine residues are simple amino acid that attaches directly to the plasmid, between the recognition site of the TEV protease and the target gene to designing a novel construction of the pET11a plasmid. The presence of these residues could also provide an unstructured linker position to facilitate accessibility and cleavage of TEV protease. In this study, we showed the purification efficiency of 3 proteins (YpDDL; XoGroEL; CjPDF) is greater than 95\%, which proves that our method brings higher purification efficiency than the previous method. Consequence, the novel pET11a plasmid construction could become an effective plasmid for the aim of harvesting high-purified recombinant proteins. Which provide a tool to easy purifying many proteins without having to intervene in structure and function of the recombinant proteins.

\section{CONCLUSION}

Recombinant proteins are necessary for biotechnology and pharmaceutical industries. They are also required for various R \& D program. Structural, functional or biochemical characterization of proteins requires a large amount of purified recombinant proteins. Few methods have been reported which can improve the expression of recombinant protein, but they cannot be universally utilized in comparison to our protocol. The use of his tag and the addition three alanine residues have resulted in high purity (over $95 \%$ ).

\section{REFERENCES}

[1] M.G. Casteleijn, A.U., S. Sarkhel, , Expression without boundaries: cell-free protein synthesis in pharmaceutical research. Int. J. Pharmaceut., 2013. vol. 440: p. 39-47.

[2] ClayBrowna, J.C.Y.M.J.L.S.a.W., Mocr: A novel fusion tag for enhancing solubility that is compatible with structural biology applications. Protein Expr Purif., 2009. vol. 63: p. 40-49. 
[3] Jon GadeHansted, L., FriederikeHög, Hans UffeSperling-Petersen, Kim KuskMortensen, Expressivity tag: A novel tool for increased expression in Escherichia coli. Journal of Biotechnology, 2011. vol. 155(3): p. 275-283.

[4] Jong-AmSong, D.-S., in-SeungPark, Kyung,-YeonHan, Jeewon Lee, A novel Escherichia coli solubility enhancer protein for fusion expression of aggregation-prone heterologous proteins. Enzyme and Microbial Technology, 2011. vol. 49(2): p. 124-130.

[5] Terpe, K., Overview of bacterial expression systems for heterologous protein production: from molecular and biochemical fundamentals to commercial systems. Applied and Enviromental Microbiology, 2006. vol. 72 : p. 211.

[6] Renaud Vincentellia, A.C., Arie Geerlofb, Atsush iKuboc, Yutaka Satouc, Christian Cambillaua, High-throughput protein expression screening and purification in Escherichia coli. Methods, 2011. vol. 55(1): p. 65-72.

[7] Jennifer L. Kopanic, M.A.-M., Sydney Zach, Srustidhar Das, Rosslyn Grosely and Paul L. Sorgen*, An Escherichia coli strain for expression of the connexin 45 carboxyl terminus attached to the 4th transmembrane domain. Frontiers in Pharmacology, 2013. vol. 4.

[8] FW, S., Protein production by auto-induction in high density shaking cultures. Protein Expr Purif., 2005. vol. 41(1): p. 207-34.

[9] Ventura*, S., Sequence determinants of protein aggregation: tools to increase protein solubility. Microbial Cell Factories, 2005. vol. 4.

[10] AlvesGamac, F., Interactions between plasmids and other mobile genetic elements affect their transmission and persistence. Plasmid, 2019. vol. 102: p. 29-36.

[11] Novagen, pET system manual, 11th edditon. 2003.

[12] Joseph E. Tropea, S.C., and David S. Waugh, High Throughput Protein Expression and Purification. Methods in Molecular Biology. 498.

[13] Yair Benitał, M.J.W., Martin C. Lok, Ian Humphery-Smith, and Ronald S. Oostingt**, Analysis of High Throughput Protein Expression in Escherichia coli*. Molecular \& Cellular Proteomics 5.9, 2006: p. 1567-1580.

[14] Johan Nilvebrant1, T.A., Sophia Hober1, Orthogonal Protein Purification Facilitated by a Small Bispecific Affinity Tag. J. Vis. Exp., 2012. vol. 59(59): p. 33370.

[15] Sreedevi Nallamsettya, R.B.K., József Tözsérb, Scott Cherrya, Joseph E. Tropeaa, and D.S.W. Terry D. Copelandc, a, EYcient site-speciWc processing of fusion proteins by tobacco vein mottling virus protease in vivo and in vitro. Protein Expression and Purifcation, 2004. vol. 38: p. 108-115.

[16] Rachel B. Kapust, a.J.T.o.e., b Terry D. Copeland,a and David S. Waugha,, The P1' specificity of tobacco etch virus protease. Biochemical and Biophysical Research Communications. vol. 294: p. 949955.

[17] Cassie M. Bryan, a., bł Janhavi Bhandari,a,bł Alberto J. Napuli,a,b David J. Leibly,a,b Ryan Choi,a,b Angela Kelley,a,b Wesley C. Van Voorhis,a,b* Thomas E. Edwardsa,c and Lance J. Stewarta,b, High-throughput protein production and purification at the Seattle Structural Genomics Center for Infectious Disease. Acta cryst F, 2011 . vol. F67: p. 1010-1014.

[18] Rachel B. Kapust, a.J.o.T.o.e., b Terry D. Copeland,a and David S. Waugha,*, The P10 specificity of tobacco etch virus protease. Biochemical and Biophysical Research Communications, 2002.vol. 294: p. 949-955.

[19] Steffen Frey *, D.G., A new set of highly efficient, tag-cleaving proteases for purifying recombinant proteins. Journal of Chromatography A, 2014. vol. 1337: p. 95-105. 
[20] Ryan Choi, a., b Angela Kelley,a,b David Leibly,a,b Stephen Nakazawa Hewitt,a,b Alberto Napulia,b and Wesley Van Voorhisa,b, Immobilized metal-affinity chromatography protein-recovery screening is predictive of crystallographic structure success. Acta Cryst. F, 2011. vol. F67: p. 998-1005.

[21] Huang, D.Z.a.Z., Effect of His-Tag on Expression, Purification, and Structure of Zinc Finger Protein, ZNF191(243-368). Bioinorganic Chemistry and Applications, 2016. vol. 2016.

[22] Huyen-Thi Tran, a.M.-K.H., a,bł Ho-Phuong-Thuy Ngo,a,b Kim-Hung Huynh,a Yeh-Jin Ahn,c Zhong Wangb,d* and Lin-Woo Kanga*, Structure of D-alanine-D-alanine ligase from Yersinia pestis: nucleotide phosphate recognition by the serine loop. Acta Cryst D, 2016. vol. D72: p. 12-21.

[23] Huyen-Thi Tran, a.T.-V.P., ał Ho-Phuong-Thuy Ngo,b Myoung-Ki Hong,b Jeong-Gu Kim,c Sang Hee Lee,d Yeh-Jin Ahne* and Lin-Woo Kangb, Crystallization and preliminary X-ray crystallographic analysis of the XoGroEL chaperonin from Xanthomonas oryzae pv. oryzae. Acta Cryst F, 2014. vol. F70: p. 604-607.

[24] Huyen Thi Tran, a.T.-V.P., a Ho-Phuong-Thuy Ngo,b Myoung-ki Hong,b Yeh-Jin Ahnc and Lin-Woo Kangb*, Expression, crystallization and preliminary X-ray crystallographic analysis of peptide deformylase from Campylobacter jejuni. Acta Cryst F, 2013. vol. F69: p. 1120-1122.

[25] Huyen Thi Tran, T.-V., Ho-Phuong-Thuy Ngo, Myoung-ki Hong, Yeh-Jin Ahnc and Lin-Woo Kangb*, Expression, crystallization and preliminary X-ray crystallographic analysis of peptide deformylase from Campylobacter jejuni. Acta Cryst F, 2013. vol. 69: p. 1120-1122.

[26] Christos P. Papaneophytou, G.K., Statistical approaches to maximize recombinant protein expression in Escherichia coli: A general review. Protein Expression and Purification 2014. vol. 94: p. 22-32.

[27] D. Esposito, D.K.C., Enhancement of soluble protein expression through the use of fusion tags. Curr. Opin. Biotechol., 2006. vol. 17: p. 353-358.

[28] Mario Lebendiker, T.D., Production of prone-to-aggregate proteins. FEBS Letters, 2014. vol. 588: p. $236-246$.

[29] Michelle E. Kimple1, Allison L. Brill1, and Renee L. Pasker1, Overview of Affinity Tags for Protein Purification. Curr Protoc Protein Sci, 2004. vol. 73.

\section{XÂY DƯNG MộT PLASMID MỚI ĐỂ GIA TĂNG HIẸU QUẢ TINH SẠCH CHO CÁC PROTEIN TÁI TỔ HỢP BIỂU HIỆN TRONG TẾ BÀO ESCHERICHIA COLI}

Tóm tắt. Ngày nay, nhu cầu trong việc cung cấp các protein tái tổ hợp đã tăng lên trong một số lĩnh vực như công nghệ thực phẩm, dược phẩm y tế, chẩn đoán lâm sàng hoặc xử lý môi trường. Các protein tái tổ hợp đã trở thành những sản phẩm được thương mại hoá và đã được sản xuất với sự gia tăng với một số lượng sản phẩm mỗi năm. Bên cạnh đó, giả định rằng sự kéo dài đuôi his-tag của plasmid $\mathrm{pET} 11 \mathrm{a}$ có thể là tạo thuận lợi cho việc loại bỏ đuôi và tinh sạch protein Trong nghiên cứu này, chín nucleotide mã hoá cho ba acid amin alanine được thêm vào vị trí theo sau đuôi hexa-histidine (his-tag) trên cấu trúc plasmid pET11a. Kết quả SDS-PAGE của mỗi protein tái tổ hợp chứa đuôi kéo dài này sau quá trình tinh sạch hầu như chỉ xuất hiện một dải trên gel. Kết quả được quan sát như nhau trên 3 protein tái tổ hợp đã xác định hiệu quả tinh sạch là trên $98 \%$. Do đó, cấu trúc plasmid mới này có thể trở thành một plasmid hiệu quả cho mục tiêu thu nhận các protein tái tổ hợp được độ tinh sạch cao.

Từ khoá. Escherichia coli (E. coli), histidine-tag, pET11a plasmid, purity effectiveness.

Ngày nhận bài: 10/10/2019

Ngày chấp nhận đăng: 14/02/2020 